Original article

\title{
Elucidating the global elapid (Squamata) richness pattern under metabolic theory of ecology
}

\author{
Rosana Talita Braga ${ }^{\mathrm{a}, *}$, Thallita Oliveira de Grande ${ }^{\mathrm{b}}$, Bruno de Souza Barreto ${ }^{\mathrm{c}}$, \\ José Alexandre Felizola Diniz-Filho ${ }^{\mathrm{d}}$, Levi Carina Terribile ${ }^{\mathrm{e}}$ \\ a Programa de Pós-Graduação em Ecologia e Evolução, Instituto de Ciências Biológicas, Universidade Federal de Goiás, Caixa Postal 131, \\ CEP 74001-970 Goiânia, Goiás, Brazil

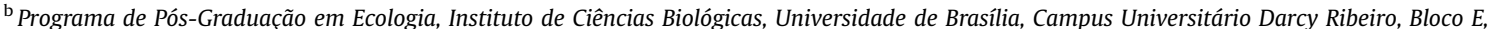 \\ Asa Norte, CEP 770910-900 Brasília, DF, Brazil \\ ${ }^{c}$ Programa de Pós-Graduação em Ciências Ambientais, Instituto de Ciências Biológicas, Universidade Federal de Goiás, Caixa Postal 131, CEP 74001-970, \\ Goiânia, Goiás, Brazil \\ d Departamento de Ecologia, Instituto de Ciências Biológicas, Universidade Federal de Goiás, Caixa Postal 131, CEP 74001-970 Goiânia, Goiás, Brazil \\ e Laboratório de Macroecologia, Universidade Federal de Goiás, Campus II, BR 364, Km 192, CEP 75801-615 Jataí, Goiás, Brazil
}

\section{A R T I C L E I N F O}

Article history:

Received 21 June 2013

Accepted 27 February 2014

Available online 22 March 2014

\section{Keywords:}

Diversity gradients

Geographically weighted regression

Macroecology

Non-stationarity

Snake

\begin{abstract}
A B S T R A C T
Environmental determinants of global patterns in species richness are still uncertain. The Metabolic Theory of Ecology (MTE) proposes that species richness patterns can be explained by environmental temperature acting on the metabolism of ectothermic organisms. However, the generality of this theory has been questioned due to its low fit to the geographic variation in species richness of different taxonomic groups. Here, we investigated whether the MTE drives elapid richness, testing the nonstationarity of the relationship between the natural logarithm of species richness $(\ln S)$ and the inverse function of temperature (1/kT) using a geographically weighted regression (GWR). The relationship between $\ln S$ and $1 / k T$ varied systematically over space and showed non-stationarity. Few tropical locations were consistent with MTE predictions, whereas other regions fitted differently. Although the slope of the GWR model ranged from low to high, the temperature did not predict species richness strongly on average and did not limit the upper values of richness. The response of richness to temperature in some areas might reflect a recent history of colonization and diversification of species across tropical and subtropical regions. In regions not affected by temperature, species richness should be structured by other biotic and abiotic interactions. This scenario reveals that the non-stationarity of the relationship would be linked to idiosyncrasies in the sample sites, which can drift the magnitude or change the relationship between species richness and temperature throughout space.
\end{abstract}

(c) 2014 Elsevier Masson SAS. All rights reserved.

\section{Introduction}

The mechanisms driving spatial the patterns of species richness have been discussed by many researchers (e.g. Gaston, 2000; Hawkins et al., 2003a; Whittaker et al., 2007; Brown, 2014; Field and Svenning, 2014), and although efforts have been intensified, there are many uncertainties concerning the ecological and evolutionary mechanisms underlying these patterns. More recently, current climate, historical processes (time to speciation and niche conservatism, variable speciation-extinction rates),

\footnotetext{
* Corresponding author.

E-mail address: talitabraga88@gmail.com (R.T. Braga).
}

habitat heterogeneity and area availability have become the most acceptable (and testable, given the measurability of these variables) hypotheses to explain diversity gradients (Jetz and Rahbek, 2001; Whittaker et al., 2001; Willig et al., 2003; Brown, 2014). Among these, climatic factors have been widely cited as powerful predictors of species richness (Hawkins et al., 2003a). However, most of the discussion concerning the relationship between climate and diversity has been based on phenomenological models (those that require an empirical, but not a mechanistic, relationship between testing variables) (O'Connor et al., 2007), so that it is difficult to establish mechanisms that potentially cause the increase in species toward low latitudes based on correlative tests alone.

The Metabolic Theory of Ecology (MTE) predicts that numerous ecological patterns can be explained by environmental 
temperature, because this variable acts on the metabolic rates of organisms (Gillooly et al., 2002; Brown et al., 2004), and Allen et al. (2002; see also Gillooly and Allen, 2007) developed a model based on the MTE to explain diversity gradients of ectothermic organisms. They proposed that the natural logarithm of species richness should be a linear function of the inverse absolute environment temperature, with slope values raging between -0.6 and -0.7 . The MTE is based on the premise that an increase in environmental temperature also increases the corporal temperature of ectothermic organisms, which leads to the acceleration of metabolic processes. This acceleration increases mutation rates, leading to high rates of speciation (see Allen et al., 2006), resulting in a high species richness in tropical regions.

The MTE has been applied to explain large-scale richness patterns (e.g. Storch, 2003; Cassemiro et al., 2007; Hawkins et al., 2007; Wang et al., 2009; McCain and Sanders, 2010). The model of Allen et al. (2002) proposed that, under the MTE, the environmental temperature should drive richness patterns when (i) the organisms under analysis are ectotherms, (ii) the taxonomic group is large, and (iii) the organisms show invariable body size and abundance across geographic space (Brown et al., 2004). Cassemiro and Diniz-Filho (2010) recently showed that deviations from these assumptions partly explain why several studies (e.g. Hawkins et al., 2007) do not support the MTE as an explanation for diversity gradients, reducing the generality and power of the model of Allen et al. (2002) to explain such gradients worldwide (see also Brown, 2014; Field and Svenning, 2014).

Most studies have predicted richness patterns using linear (Allen et al., 2002; Brown et al., 2004) or curvilinear (Algar et al., 2007) estimations of global regressions, without understanding how the relationships vary from one region to other. Cassemiro et al. (2007), however, used geographically weighted regression (GWR) to solve the problem of non-stationarity in data and showed that the relationship between richness patterns and temperature varies systematically across space, and in some regions this relationship is not significant. Following this reasoning, it is probable that there is not a universal metabolic scale, and thus generalizations of MTE must be evaluated, to improve the understanding of which geographic domain of the MTE best predicts the richness patterns. Consequently, other factors might limit species richness (Hawkins et al., 2003b). Moreover, although the MTE assumes that a relationship between temperature and ectotherm richness exists, some groups apparently do not follow the theory expectations (e.g., Lima-Ribeiro et al., 2010). Thus, these other factors that are potentially influential on the theory require a better investigation of how the richness of distinct taxonomic groups can be explained by the MTE.

Here, we investigated whether the MTE drives the global pattern of elapid species richness. The Elapidae is a group of venomous snakes mostly distributed across tropical regions (Terribile et al., 2009). Species from the New World are predominantly fossorial or semi-fossorial, whereas species' habits in the Old World can vary from terrestrial to arboreal (Asian, African and Australian species) and aquatic (Australian species). Some evidence suggests that temperature is associated with the spatial variation in elapid richness, although other factors might also constrain the latitudinal pattern of species distribution in this group (see Terribile et al., 2009). We tested the non-stationarity of the relationship between species richness and temperature using a GWR. This type of regression analysis has been recently applied in many macroecological analyses (e.g. Fotheringham et al., 2002; Wang et al., 2005; Bickford and Laffan, 2006; Cassemiro et al., 2007; Terribile and Diniz-Filho, 2008) and has the advantage of describing the relationship between $Y$ (response variable) and $X$ (predictor variable) by a regression for each location, or "cell", using spatial weights, rather than estimating a single set of regression coefficients.

\section{Materials and methods}

\subsection{Species distribution and climate data}

We obtained geographic distribution maps for 223 species, following the taxonomic classification of the Reptile Systematics Working Group of the German Herpetological Society (Uetz, 2007). Marine species were excluded from analyses. For the New World species, maps were obtained from Campbell and Lamar (2004), supplemented with new species described by Renjifo and Lundberg (2003), Alvarado-Díaz and Campbell (2004) and Lavin-Murcio and Dixon (2004). For Old World species, we used those described by Branch (1988, 1998), Latifi (1991), Arnold (2002), Arnold and Ovenden (2002), Broadley and Doria (2003), Spawls et al. (2004), Ananjeva et al. (2006), Vogel (2006), Dobiey and Vogel (2007), complemented by those of Cherlin (1981), Orlov and Tuniyev (1990), Tuniyev and Ostrovskikh (2001), Khan (2002), Mallow et al. (2003) and Geniez and Tynié (2005). Maps for Australian elapid snakes were obtained from Wilson and Swan (2003). We reprojected the distribution maps on a regular grid of $110 \times 110 \mathrm{~km}$ (latitude $\times$ longitude) with an equal-area projection. Species richness was obtained by summing the species occurrence in each cell grid (Fig. 1; see also Terribile et al., 2009). Cells with less than $50 \%$ land area were excluded from the analyses. Environmental temperature (extracted from WorldClim in Celsius degrees, Hijmans et al., 2005) was also projected onto the same grid.

According to the MTE model (Allen et al., 2002), the natural logarithm of species richness ( $\ln \mathrm{S}$ ) decreases with increasing $1 / k T$, where $k$ is Boltzmann's constant and $T$ is the environmental temperature in Kelvin. Thus, to obtain the explanatory variable proposed by the MTE, we converted the temperature from degrees Celsius to Kelvin and rescaled it using the equation $T_{\mathrm{MTE}}=1 / k T$, the inverse function of temperature.

\subsection{Statistical analysis}

To investigate the effects of temperature on elapid species richness, we regressed the natural logarithm of richness to the inverse function of temperature using a global OLS regression model as well as he GWR approach (Fotheringham et al., 2002). Calibration of the GWR model followed a local weighted least squares approach. Different to an ordinary weighted least squares, the GWR assigns weights according to the spatial proximity of all other data to the location $i$ to calibrate the regression coefficients on location $i$. These weights ensure that locations near to each other impose a greater influence on the calibration than locations further away.

The weights are usually obtained via a spatial kernel function, based on fixed and adaptive kernels. In a fixed kernel function, an optimum spatial kernel (bandwidth) is obtained and applied over the study area. However, as highlighted by Páez et al. (2002a,b) and Fotheringham et al. (2002), a fixed kernel approach can produce a large local estimation variance in areas where data are sparse, potentially masking subtle local variations in areas where data are dense. The adaptive kernel function seeks a certain number of nearest neighbors to adapt the spatial kernel and ensure a constant size of local samples. This kernel function might represent a more reasonable means of representing the degree of spatial nonstationarity in the study area. In this study, the adaptive kernel function was employed.

To obtain an optimum size of nearest neighbors for the adaptive kernel, a common approach is to minimize the Akaike 


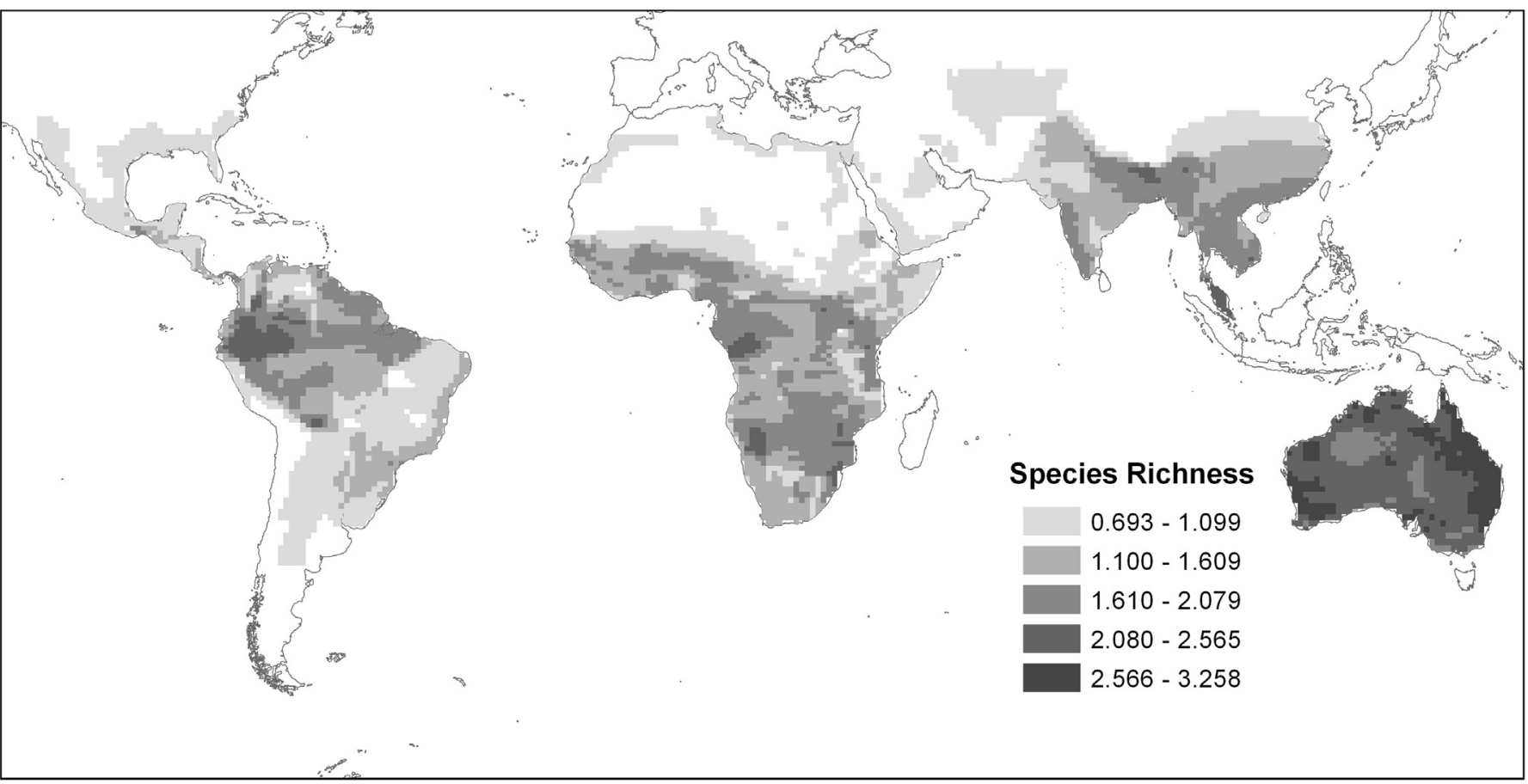

Fig. 1. Global pattern of Elapidae species richness.

Information Criterion (AIC) of the GWR model (Fotheringham et al., 2002). The estimated parameters of the GWR are highly dependent on bandwidth, and whereas this bandwidth increases, the GWR estimates tend to those from a global OLS regression model (Wang et al., 2005). Moreover, to verify whether richness and temperature show a non-stationary relationship, we applied a Monte Carlo test over GWR. We performed all analyses on GWR
3.0, software for geographically weighted regression (Charlton et al., 2003).

Finally, large-scale patterns of species richness occasionally exhibit a marked pattern when plotted against explanatory variables. For a better understanding of how temperature limits species richness, we regressed the natural logarithm of richness to the inverse function of temperature using a quantile regression

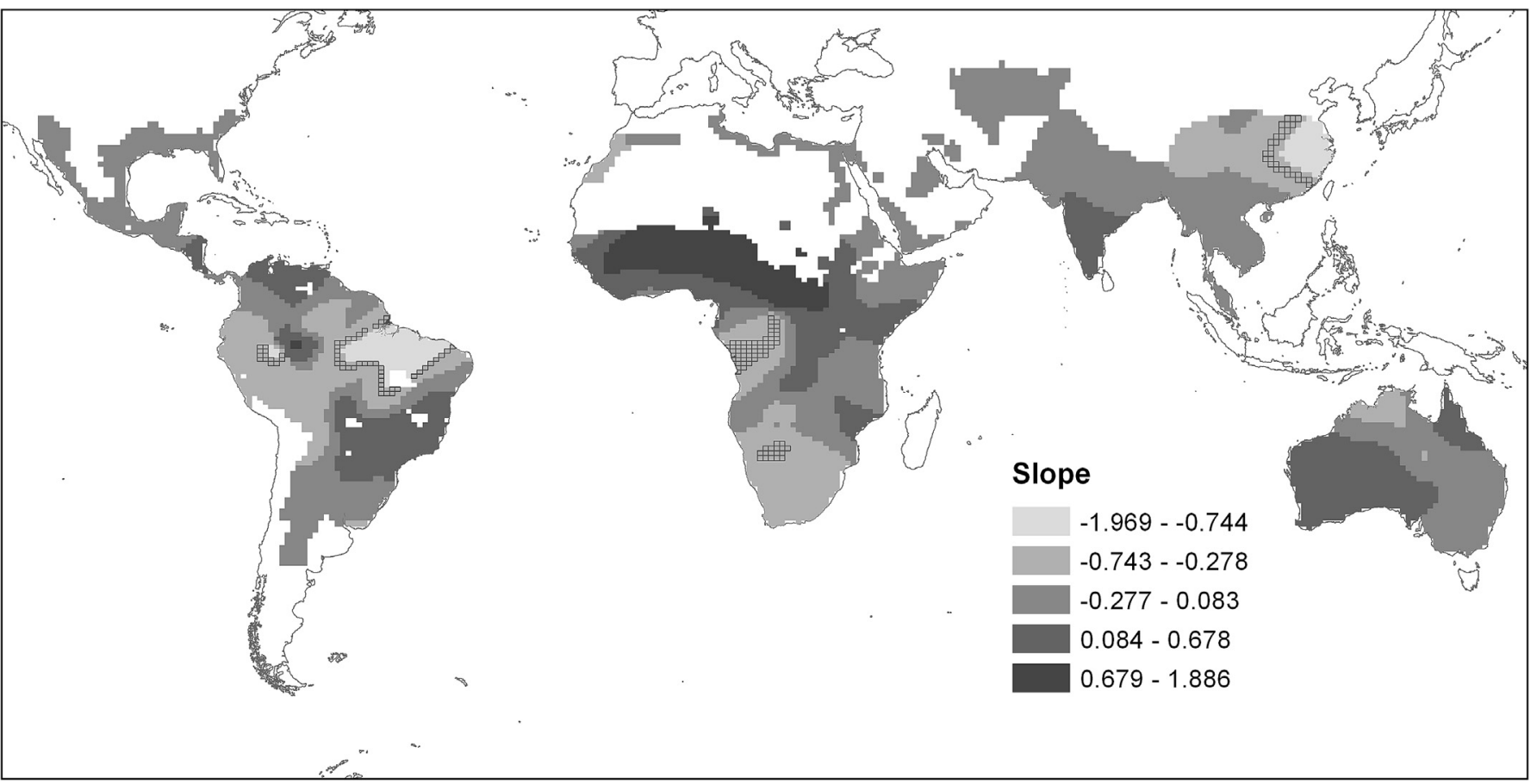

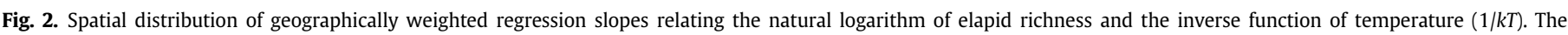
outlined cells represent the locations where the values of the slope are within the range predicted by the MTE. 
approach (Cade and Noon, 2003), to investigate the behavior of the relationship from deciles $70 \%-90 \%$. Thus, we analyzed whether the inverse function of temperature constrains the upper limit of elapid species richness.

\section{Results}

The Monte Carlo test of GWR shows that the relationship between temperature and species richness was non-stationary $(p<0.001)$ and increasing the temperature can lead to increased or decreased species richness, depending on where the relationship is established (Fig. 2). The MTE explained species richness in a few regions of the world, usually concentrated in the tropical regions. Slope values within the range predicted by the MTE $(-0.6$ to -0.7$)$ appear only in South America, Africa and Southern Asia (Fig. 2). The global regression model (OLS) and the GWR model did not have the same statistical performance (GWR ANOVA, $F(81 ; 6088)=329.756$, $p<0.001$ ). The ANOVA is a simple test to identify whether OLS and GWR have the same size of error variance. Although the OLS slope was significant, it was not consistent with the MTE (global slope $=-0.015, R^{2}=0.034 ; t=-14.891, \mathrm{df}=6170, p<0.001$ ). However, the statistical significance should be interpreted with caution, because the OLS overestimates the degrees of freedom due to spatial autocorrelation in the residuals.

We also observed that temperature was not a powerful predictor of elapid species richness in the GWR (Fig. 3) or OLS fit. The marked pattern in the scatterplot (Fig. 4) indicated that species richness might be somehow limited by temperature. However, the distribution of species richness in the upper quantiles was not explained by temperature in deciles $90 \%$ (slope $=-0.05, t=1.25$, $p=0.21$ ), 80\% (slope $=-0.08, t=-1.63, p=0.1)$ and was weakly influenced in decile 70\% ( slope $=-0.18, t=-7.25, p<0.01$ ) (Fig. 4). Thus, temperature did not limit species richness, but it is reasonable to point out that the density of points in the upper quantiles tended to be low, which influenced the fit of the regression quantile model (Fig. 4).

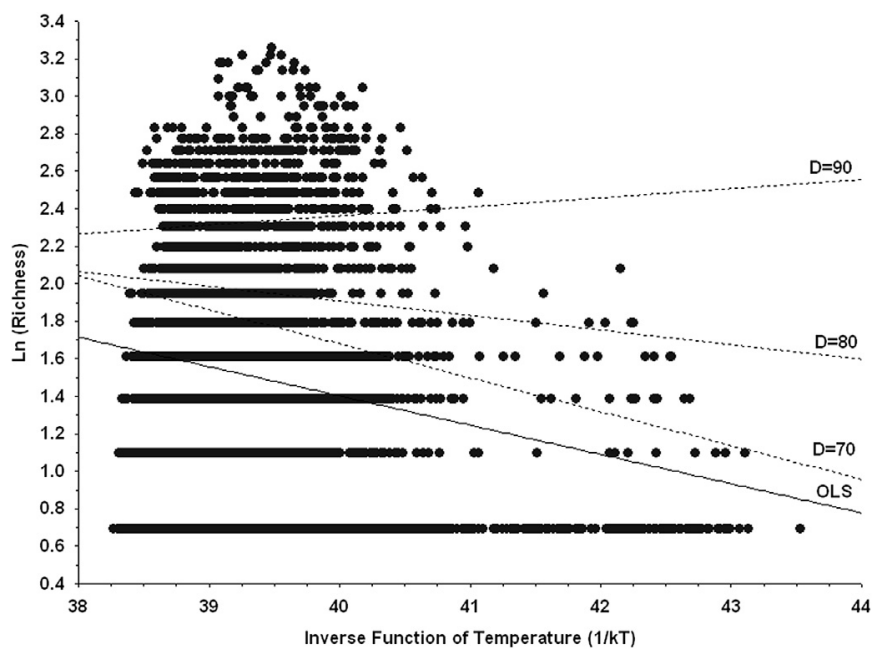

Fig. 4. Relationship between the natural logarithm of elapid species richness and the inverse function of temperature $(1 / k T)$. The full regression line was fitted by the OLS approach and dotted regression lines were fitted by the quantile regression approach on $70 \%, 80 \%$ and $90 \%$ deciles (D). See results for detailed statistics.

\section{Discussion}

In the model proposed by Allen et al. (2002), the decreasing temperature should lead to a predictable reduction in the number of species of ectothermic organisms and this relationship, after rescaling the variables, had a slope between -0.6 and -0.7 , following the overall reasoning developed in the MTE (see Brown et al., 2004). However, the relationship between log-transformed richness and temperature can assume much more complex forms (Algar et al., 2007; Hawkins et al., 2007;Rombouts et al., 2011) or can even vary systematically across geographical space (Cassemiro et al., 2007; see also Algar et al., 2007; Terribile and Diniz-Filho, 2008, Brown, 2014; Field and Svenning, 2014). According to these

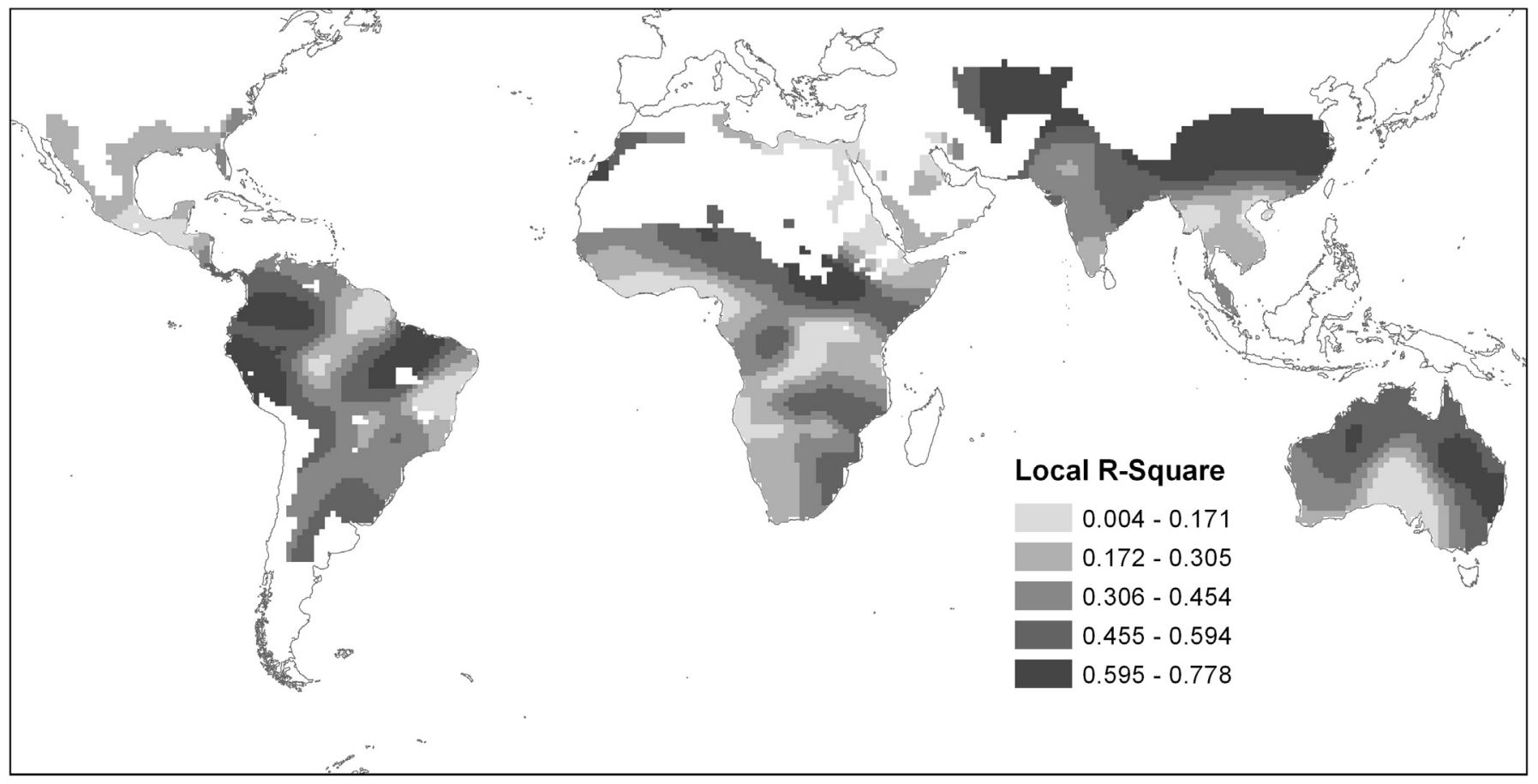

Fig. 3. Local coefficient of determination $\left(R^{2}\right)$ from the relationship between the natural logarithm of elapid species richness and the inverse function of temperature $(1 / k T)$. 
previous studies, our results showed that the global regression slope for the relationship between Elapidae richness and the inverse function of temperature did not correspond with the predicted slope of the MTE.

The local slopes from the GWR were mostly outside the range predicted by the MTE. In regions where the MTE-predicted slopes were found, the power of the explanation $\left(R^{2}\right)$ of temperature varied. This demonstrates that although these areas have slopes that are congruent with MTE expectations, temperature drives the macroecological pattern of species richness differentially. Regions where the coefficient of determination did not show high values indicate that temperature via MTE predictions is not the only factor that drives richness. Indeed, Terribile et al. (2009) showed that although temperature was an important predictor of global patterns of elapid richness, there is evidence that historical effects based on differential speciation rates and lineage diversification across regions determined regional differences in species richness for this group of snakes. If so, although the pattern of richness responds to temperature variation in some regions, it still reflects a recent history of colonization and diversification within tropical and subtropical regions (Sanders and Lee, 2008). This may, at least in part, explain in the observed non-stationarity of the relationship between richness and temperature.

Besides the violation of non-stationarity, other assumptions of the MTE should be considered for understanding the low fit of the MTE model (Cassemiro and Diniz-Filho, 2010). For the Elapidae, assumptions of body size and abundance invariance among sample units are not valid, even though the elapids are a diverse group. A possible cause for this low predictive power is the variation in abundance and body size of Elapidae species, as shown by Terribile et al. (2009). Although data on body size are relatively easy to obtain and the variation along space can be measured, abundance at broad scales is difficult to estimate, mainly when these data are required for many species (Kaspari, 2004; McCain and Sanders, 2010). Thus, although the MTE well explains the richness of high diversity groups, as shown by some studies (Martínez del Rio, 2008; Cassemiro and Diniz-Filho, 2010), is difficult to test this important assumption when applied to broad-scale richness patterns.

Furthermore, the ability for the thermoregulation of reptiles is expected to limit the influence of temperature on species richness and on the test of the MTE predictions. However, most elapid snakes are 'thermoconformers' and have a poor ability to maintain body temperature independent of environmental variation, as they spend long periods inactive in refugia and have relatively sedentary behavior (Webb and Shine, 1998). Thus, thermoregulation is not expected to influence the tests for the MTE prediction within this group (see also McCain and Sanders, 2010).

The difficulty of conceiving temperature as the only and power expounder of the species richness pattern, as shown by our results, was discussed by Brown et al. (2004). The authors discuss that although the high productivity (resource availability) and low seasonality of tropical regions represent one explanation for the high species richness, the relationship between productivity and richness is permeated by temperature. The kinetic effect of temperature on individual metabolism might lead to an increase in both richness and productivity. Since productivity increases with increasing temperature, Brown et al. (2004) assume the difficulty of distinguishing the kinetic effects of high temperature from effects of resources availability in high productivity conditions. Therefore, it is possible that this dissociation between productivity and temperature hinders the understanding of the particular effect of temperature on species richness. It is necessary to understand which evolutionary and ecological processes are temperaturedependent and how they generate and maintain local species richness (Brown, 2014). The effect of temperature is not only on biodiversity and latitudinal gradients - due to higher evolutionary rates, but also on ecological interactions - due to an increase of the coevolutionary processes (see Brown, 2014; Field and Svenning, 2014).

The differences observed between the global and local results in this study might indicate that processes and predictor variables differentially influence the response according to the spatial extent adopted (Foody, 2004; Fang et al., 2012). Bickford and Laffan (2006) showed that despite the positive relationship between fern richness and water availability in Australia, this relationship varies spatially in complex ways. As the spatial extent increases, the model performance is hampered because the information from variables becomes grouped, so that all sites have the same value of the regression coefficient, which leads to a loss of information that could be avoided by local regression models. Thereby, the GWR models explain the tested variable at different spatial scale in accord to geographic weighting in the model. This is because even though the parameters vary from one location to another, the model is able to discern such differences and generates values of the regression coefficient for each location (Fotheringham et al., 2002). Such a more-detailed analysis enabled us to identify tropical areas where temperature appears to limit richness according to the MTE predictions (see Fig. 2), although the importance of temperature (and possibly its interaction with other factors not measured here) in other areas of the tropical region cannot be neglected, as shown by the high values of the coefficient of determination across most of the areas with a high species richness.

Finally, the applicability of MTE becomes much reduced. This is mainly due to the differences that have been observed in the relationship between temperature and species richness of the same taxonomic group at different spatial scales of analysis (Cassemiro et al., 2007; Hawkins et al., 2007; Terribile and Diniz-Filho, 2008; Lima-Ribeiro et al., 2010; this study). Although temperature appears to affect species distribution according to the MTE in some specific regions, the pattern of elapid species richness presumably reflects the coupled effect of biotic and abiotic variables, resulting in non-stationary relationships between temperature and richness when analyzed on a local scale. The way that each taxonomic group responds to these locally variable factors makes it difficult to define the real contribution of temperature (as proposed by the MTE) to species richness at large spatial scales.

\section{Acknowledgments}

Research by R.T. Braga was funded through a PhD studentship from Coordination of Higher Education Personnel Improvement (CAPES). T.O. de Grande was funded through a Msc studentship from National Council for Scientific and Technological Development (CNPq). B. de S. Barreto was funded through a PhD studentship from (CNPq). Work by J.A.F. Diniz-Filho is supported by CNPq researcher fellowship. L.C. Terribile receives financial support from CNPq (process $n^{\circ}$ 473788/2009-8 and 563727/2010-1).

\section{References}

Algar, A.C., Kerr, J.T., Currie, D.J., 2007. A test of metabolic theory as the mechanism underlying broad-scale species-richness gradients. Glob. Ecol. Biogeogr. 16, $170-178$.

Allen, A.P., Brown, J.H., Gillooly, J.F., 2002. Global biodiversity, biochemical kinetics and the energetic equivalence rule. Science 297, 1545-1548.

Allen, A.P., Gillooly, J.F., Savage, V.M., Brown, J.H., 2006. Kinetic effects of temperature on rates of genetic divergence. Proc. Natl. Acad. Sci. U.S.A. 103, 9130-9135.

Alvarado-Díaz, J., Campbell, J.A., 2004. A new montane rattlesnake (Viperidae) from Michoacán, Mexico. Herpetologica 60, 281-286.

Ananjeva, N.B., Orlov, N.L., Khalikov, R.G., Darevsky, I.S., Ryabov, S.A., Barabanov, A.V., 2006. The Reptiles of Northern Eurasia: Taxonomic Diversity, Distribution, Conservation Status, first ed. Pensoft Publishers, Sofia-Moscow. 
Arnold, E.N., 2002. A Field Guide to the Reptiles and Amphibians of Britain and Europe, second ed. Harper Collins, London.

Arnold, E.N., Ovenden, D.W., 2002. Reptiles and Amphibians of Europe, second ed. Princeton University Press, Princeton.

Bickford, S.A., Laffan, S.W., 2006. Multi-extent analysis of the relationship between pteridophyte species richness and climate. Glob. Ecol. Biogeogr. 15, 588-601.

Branch, B., 1988. Field Guide to the Snakes and Other Reptiles of Southern Africa, first ed. New Holland, London.

Branch, B., 1998. Field Guide to Snakes and Other Reptiles of Southern Africa, third ed. Ralph Curtis Books Publishing, Sanibel.

Broadley, D.G., Doria, C.T., 2003. Snakes of Zambia: An Atlas and Field Guide, first ed. Edition Chimaira, Frankfurt.

Brown, J.H., Gillooly, J.F., Allen, A.P., Savage, V.M., West, G.B., 2004. Toward a metabolic theory of ecology. Ecology 85, 1771-1789.

Brown, J.H., 2014. Why are there so many species in the tropics? J. Biogeogr. 41, 8 22.

Cade, B., Noon, B., 2003. A gentle introduction to quantile regression for ecologists. Front. Ecol. Environ. 1, 412-420.

Campbell, J.A., Lamar, W.W., 2004. The Venomous Reptiles of the Western Hemisphere vols. I and II. Cornell University Press, New York.

Cassemiro, F.A.S., Barreto, B.S., Rangel, T.F.L.V.B., Diniz-Filho, J.A.F., 2007. Non-stationarity, diversity gradients and the metabolic theory of ecology. Glob. Ecol. Biogeogr. 16, 820-822.

Cassemiro, F.A.S., Diniz-Filho, J.A.F., 2010. Gradientes de diversidade e a teoria metabólica da ecologia. Oecol. Aust. 14, 490-503.

Charlton, M., Fotheringham, S., Brunsdon, C., 2003. GWR 3. Software for Geographically Weighted Regression. Spatial Analysis Research Group, Department of Geography, University of Newcastle upon Tyne, Englan.

Cherlin, V.A., 1981. The new saw-scaled viper Echis multisquamatus sp. nov. from south-western and Middle Asia. Trudy Zool. Inst. 101, 92-95 (in Russian).

Dobiey, M., Vogel, G., 2007. Venomous Snakes of Africa, first ed. Edition Chimaira, Frankfurt.

Fang, J., Wang, Z., Tang, Z., Brown, J.H., 01/2012. Large-scale patterns of tree species richness and the metabolic theory of ecology. Glob. Ecol. Biogeogr. 21, 508-512.

Field, R., Svenning, J.C., 2014. Tropical diversity and the energetic ecology of the Red Queen. J. Biogeogr. 41, 6-7.

Foody, G.M., 2004. Spatial nonstationarity and scale-dependency in the relationship between species richness and environmental determinants for the sub-Saharan endemic avifauna. Glob. Ecol. Biogeogr. 13, 315-320.

Fotheringham, A.S., Brunsdon, C., Charlton, M., 2002. Geographically Weighted Regression: the Analysis of Spatially Varying Relationships. Wiley, Chichester.

Gaston, K.J., 2000. Global patterns in biodiversity. Nature 405, 220-227.

Geniez, P., Tynié, A., 2005. Discovery of a population of the critically endangered Vipera darevskii Vedmederja, Orlov \& Tuniyev, 1986 in Turkey, with new elements on its identification (Reptilia: Squamata: Viperidae). Herpetozoa 18, 2533.

Gillooly, J.F., Brown, J.H., West, G.B., Savage, V.M., Charnov, E.L., 2002. Effects of size and temperature on metabolic rate. Science 293, 2248-2251.

Gillooly, J.F., Allen, A.P., 2007. Linking global patterns in biodiversity to evolutionary dynamics using metabolic theory. Ecology 88, 1890-1894.

Hawkins, B.A., Diniz-Filho, J.A.F., Bini, L.M., Araújo, M.B., Field, R., Hortal, J., Kerr, J.T., Rahbek, C., Rodriguez, M.A., Sanders, N.J., 2007. Metabolic theory and diversity gradients: where do we go from here? Ecology 88, 1898-1902.

Hawkins, B.A., Field, R., Cornell, H.V., Currie, D.J., Guégan, J.F., Kaufman, D.M., Kerr, J.T., Mittelbach, G.G., Oberdorff, T., O’brien, E.M., Porter, E.E., Turner, J.R.G., 2003a. Energy, water and broad-scale geographic patterns of species richness. Ecology 84, 3105-3117.

Hawkins, B.A., Porter, E.E., Diniz, J.A.F., 2003b. Productivity and history as predictors of the latitudinal diversity gradient of terrestrial birds. Ecology 84, 1608-1623.

Hijmans, R.J., Cameron, S.E., Parra, J.L., Jones, P.G., Jarvis, A., 2005. Very high resolution interpolated climate surfaces for global land area. Int. J. Climatol. 25, 1965-1978.

Jetz, W., Rahbek, C., 2001. Geometric constraints explain much of the species richness pattern in African birds. Proc. Natl. Acad. Sci. U.S.A. 98, 5661-5666.

Kaspari, M., 2004. Using the metabolic theory of ecology to predict global patterns of abundance. Ecology 85, 1800-1802.

Khan, S., 2002. Venomous terrestrial snakes of Pakistan. Available at: http://www. wildlifeofpakistan.com/ReptilesofPakistan/ venomousterrestrialsnakesofPakistan.htm (accessed 03.04.07).
Latifi, M., 1991. The Snakes of Iran, English Edition. Society for the study of Amphibians and Reptiles, Oxford.

Lavin-Murcio, P.A., Dixon, J.R., 2004. A new species of coral snake (Serpentes, Elapidae) from the Sierra de Tamaulipas, Mexico. Phyllomedusa 3, 3-7.

Lima-Ribeiro, M.S., Rangel, T.F.L.V.B., Pinto, M.P., Moura, I.O., Melo, T.L., Terribile, L.C., 2010. Padrões espaciais da riqueza de espécies de viperídeos na América do Sul: temperatura ambiental vs. cinética-bioquímica. Acta Sci. Biol. Sci. 32, 153-158.

Mallow, D., Ludwig, D., Nilson, G., 2003. True Vipers: Natural History and Toxinology of Old World Vipers. Krieger Publishing Company, Malabar.

Martínez del Rio, M.C., 2008. Metabolic theory or metabolic models? Trends Ecol. Evol. 23, 256-260.

McCain, C.M., Sanders, N.J., 2010. Metabolic theory and elevational diversity of vertebrate ectotherms. Ecology 91, 601-609.

O'Connor, M.P., Kemp, S.J., Agosta, S.J., Hansen, F., Sieg, A.E., Wallace, B.P., Mcnair, J.N., Dunham, A.E., 2007. Reconsidering the mechanistic basis of the metabolic theory of ecology. Oikos 116, 1058-1072.

Orlov, N.L., Tuniyev, B.F., 1990. Three species in the Vipera kaznakowi complex (Eurosiberian Group) in the Caucasus: their present distribution, possible genesis, and phylogeny. Asia. Herpet. Res. 3, 1-36.

Páez, A., Uchida, T., Miyamoto, K., 2002a. A general framework for estimation and inference of geographically weighted regression models: 1. Location-specific kernel bandwidths and a test for locational heterogeneity. Environ. Plan. A 34, 733-754.

Páez, A., Uchida, T., Miyamoto, K., 2002b. A general framework for estimation and inference of geographically weighted regression models: 2. Spatial association and model specification tests. Environ. Plan. A 34, 883-904.

Renjifo, J.M., Lundberg, M., 2003. Una especie nueva de serpiente coral (Elapidae Micrurus), de la region de Urra, municipio de Tierra Alta, Cordoba, noroccidente de Colômbia. Rev. Acad. Colombiana Cienc. Exact. Fís. Nat. 27, 141-144.

Rombouts, I., Beaugrand, G., Ibaňez, F., Chiba, S., Legendre, L., 2011. Marine copepod diversity patterns and the metabolic theory of ecology. Oecologia 166 (2), 349355.

Sanders, K.L., Lee, M.S.Y., 2008. Molecular evidence for a rapid late-Miocene radiation of Australasian venomous snakes (Elapidae, Colubroidea). Mol. Phylogenet. Evol. 46, 1180-1188.

Spawls, S., Howell, K., Drewes, R., Ashe, J., 2004. A Field Guide to the Reptiles of East Africa. A \& C Black Publishers, London.

Storch, D., 2003. Comment on "Global biodiversity, biochemical kinetics, and the energetic-equivalence rule". Science $299,346$.

Terribile, L.C., Diniz-Filho, J.A.F., 2008. Spatial patterns of species richness in new world coral snakes and the metabolic theory of ecology. Acta Oecol. 35, 163173.

Terribile, L.C., Olalla-Tárraga, M.A., Diniz-Filho, J.A.F., Rodríguez, M.A., 2009 Ecological and evolutionary components of body size: geographic variation of venomous snakes at the global scale. Biol. J. Linn. Soc. 98, 94-109.

Tuniyev, B.S., Ostrovskikh, S.V., 2001. Two new species of vipers of 'kaznakovi' complex (Ophidia, Viperinae) from the Western Caucasus. Russ. J. Herpetol. 8, $117-126$.

Uetz, P., 2007. The reptile database. Available at: http://www.reptile-database.org (accessed 10.05.07).

Vogel, G., 2006. Venomous Snakes of Asia, first ed. Edition Chimaira, Frankfurt.

Wang, Q., Ni, J., Tenhunen, J., 2005. Application of a geographically-weighted regression analysis to estimate net primary production of Chinese forest ecosystems. Glob. Ecol. Biogeogr. 14, 379-393.

Wang, Z., Brown, J.H., Tang, Z., Fang, J., 2009. Temperature dependence, spatial scale, and tree species diversity in eastern Asia and North America. Proc. Natl. Acad. Sci. U.S.A. 106, 13388-13392.

Webb, J.K., Shine, R., 1998. Thermoregulation by a nocturnal elapid snake (Hoplocephalus bungaroides) in the Southeastern Australia. Physiol. Zool. 71, 680-692.

Whittaker, R.J., Nogués-Bravo, D., Araújo, M.B., 2007. Geographical gradients of species richness: a test of the water-energy conjecture of Hawkins et al. (2003) using European data for five taxa. Glob. Ecol. Biogeogr. 16, 76-89.

Whittaker, R.J., Willis, K.J., Field, R., 2001. Scale and species richness: towards a general, hierarchical theory of species diversity. J. Biogeogr. 28, 453-470.

Willig, M.R., Kaufman, D.M., Stevens, R.D., 2003. Latitudinal gradients of biodiversity: pattern, process, scale, and synthesis. Annu. Rev. Ecol. Evol. Syst. 34, 273309.

Wilson, S., Swan, G., 2003. Reptiles of Australia, second ed. Princeton University Press, Princeton. 